\title{
Performance Test of VHF-HF-based Emergency Data Communication System between the Sardjito Hospital and District Hospital in the Isolated and Disaster-prone Areas
}

\author{
Singgih Hawibowo ${ }^{1}$, Sunarno ${ }^{1}$, Memory Motivanisman Waruwu, ${ }^{1, *}$, Yakub Fahim Luckyarno ${ }^{2}$, Rony Wijaya ${ }^{3}$, and \\ Samuel Kristiyana ${ }^{4}$ \\ ${ }^{1}$ Department of Nuclear Engineering and Engineering Physics, Universitas Gadjah Mada, Yogyakarta, Indonesia \\ ${ }^{2}$ International College, King Mongkut's Institute of Technology Ladkrabang, Bangkok, Thailand \\ ${ }^{3}$ Production House Unit, Faculty of Medicine, Universitas Gadjah Mada, Yogyakarta, Indonesia \\ ${ }^{4}$ Institut Sains \& Teknologi AKPRIND Yogyakarta, Indonesia
}

\begin{abstract}
The topography of Gunungkidul area in the Province of Yogyakarta, Indonesia, consisting of hills and limestone mountains. It becomes the potential factor of landslide occurrences. Especially in the rainy season, the soils in the hills become softer and it increases the possibility to cause a landslide. This condition has became the concern of many people, especially the residents who live in the landslide-prone area. This topography is also one of the factors for health centre in a certain area becomes isolated due to the inability of telecommunication signal services from the provider to reach that area, which is called a blank area. That situation makes an inability to contact the nearest district hospital to ask for support in an emergency case. This research focuses on the performance test of the emergency data communication system by using several types of data. The system uses Very High Frequency (VHF) $144 \mathrm{MHz}$ and High Frequency (HF) 7.08 MHz as the data carrier and a software to interpret the text and image to be modulated onto the data carrier. That system is called a virtual hospital, means that even though the health center is located in a blank area, but specialists from the Sardjito Hospital can still deliver advices to support the health center in maintaining the medical service quality by using the VHF-HF-based emergency data communication system. Based on the results of the system's performance test between the Wonosari Gunungkidul District Hospital and the Sardjito Hospital with the distance of $40 \mathrm{~km}$, the receiving quality of the data transmission for text and image are $95 \%$ and $55.33 \%$, respectively.
\end{abstract}

\section{Introduction}

Gunungkidul is a district in Yogyakarta which prone to disaster. Until 2015, the disaster data records published by the province government shows that Gunungkidul is on the top three areas prone to disaster, after Kulonprogo and Bantul. The location and geographical of Gunungkidul becomes the main factor of several disasters, such as drought, hurricane, and landslide. The topography of Gunungkidul, consisting of hills and limestone mountains, becomes the factor of landslide occurrences. Especially in the rainy season, the soils in the hills become softer and it increases the possibility to cause a landslide. That condition has become the concern of many people, especially the residents who live in the landslide-prone area. The residents should have an understanding of how dangerous the landslide can be, so that the resident's disaster-resilience is increased and all people can be aware of the signs of landslide and do the evacuation immediately.

The awareness improvement on landslide disaster is not only done by the government, but also it should include the participation of the residents around the landslide-prone area. One way to increase the awareness of the residents and as a test for the disaster awareness plan made by the government of the Gunungkidul is through a prevention simulation of landslide disaster. By doing the simulation, the result can be an input for Gunungkidul government, hospitals, and Gunungkidul residents in order to prepare a plan of disaster prevention for the district (Regional Disaster Plan, RDP) and a disaster prevention in the healthcare section for the Ministry of Health and hospitals (Hospital Disaster Plan, HDP). Based on that story, a project from Swedish International Development Cooperation Agency (SIDA), in cooperation with Umea University, UGM, and the government of Gunungkidul, is about an activity for

* Corresponding author: morymw@gmail.com 
landslide disaster prevention at Gunungkidul. In this case, we take a role in the training process of how to use the emergency communication system for all staffs in the Ministry of Health in Gunungkidul so that it can be a pioneer in the idea of virtual hospital. Briefly, a virtual hospital is a health consultation service between patient in the isolated area (due to the topography so the telecommunication signal cannot achieve the area) and doctors in the central hospital in downtown (Sardjito Hospital).

\section{Theoretical Background}

On 2005 hurricane Katrina rendered unusable a significant percentage of the voice and data communication infrastructure in coastal communities of Louisiana and Mississippi. In the days following the hurricane, amateur radio operators arrived in the devastated areas, provided local emergency communication, both voice and data, and established communication with other regions of the United States, using primarily mobile radio transceivers [1].

For decades, the high-frequency (HF) band has been recognized as the primary means of long-range wireless communications. The HF band lies within 2-30 MHz of the electromagnetic spectrum. In this part of the spectrum, propagation via direct wave, surface wave, near-vertical incidence skywave (NVIS), and skywave provides a means of communication, from line-of-sight (LOS) to beyondline-of-sight (BLOS) and over-the-horizon (OTH) ranges [2].

All standard SSTV modes utilize a unique digital code that identifies the mode to a receiving system. The code is called the VIS, or Vertical Interval Signal code. Although the entire calibration header is often referred to as the "VIS code", the code itself is only a part of it. The seven-bit code is transmitted least-significant bit (LSB) first, and uses "even" parity [3].

There are series of experiments and attempts by different radio amateurs but most of them use proprietary transmission systems. One of the oldest and wide spread methods is slow scan television (SSTV). There are different modes of transmission. The team decided to focus in ROBOT36 because is relatively wide spread and it able to transmit colour images. In order to achieve the desired system in small, lightweight system an raspberry $\mathrm{Pi}$ was used for image capture, signal processing and signal generation and a custom RF transmitter was developed [4].

In recent years, small satellites have begun to draw attention due to reconstruction in low cost of manufacture and faster building time. In this project, radio transmitter system is built for nano and micro satellites. Transmitter broadcasts $1 \mathrm{~W}$ power in $435 \mathrm{MHz}$ free amateur satellite communication band, and also has software defined radio structure in all modules except up-conversion part. Design was capable of DE0-Nano evaluation board connection; it is regard of PC104 connector structure standard. FSK modulation and AX.25 data link layer protocol are designed using digital circuit in FPGA and implemented with VHDL [5].
The radio-based data communication subsystem (DCS) between trains and wayside is a key factor for safe and efficient operation of a communication-based train control (CBTC) system. The train control system is now able to provide efficient, flexible, and cost-effective operation by using cutting-edge information and communication technologies collectively referred to as CBTC. CBTC technology has become standardized, and its commercialization trend has witnessed a drastic growth in recent years [6].

Secret sharing is an important cryptographic primitive for enabling multi-party computation. A secret image sharing (SIS) scheme encrypts the secret image into few meaningless shadows or share images. These shadows are distributed among the legitimate set of participants. Only the qualified subsets of participants can co-operate to reveal the secret image and forbidden subset fails to retrieve any information about the same [7].

\section{Proposed Method}

This research focuses on the performance test of the emergency data communication system by using several types of data. The system uses Very High Frequency (VHF) $144 \mathrm{MHz}$ and High Frequency (HF) $7.08 \mathrm{MHz}$ as the data carrier and a software to interpret the text and image to be modulated onto the data carrier. That system is called a virtual hospital [8], means that even though the District Hospital or Public Health Centre is located in the blank area, but the specialists from the Sardjito Hospital can still support them to maintain the medical service quality by using the VHF-HF-based emergency data communication system. Based on the results of the system's performance test between the Wonosari Gunungkidul District Hospital and the Sardjito Hospital with the distance of $40 \mathrm{~km}$.

Primary data retrieval uses repeater signal test data by sending the audio data, sending the text data and sending the image data. Software MixW 3.11g is used for data communication experiments. Software Mobile Radio is used to perform robust design of emission and coverage of repeater, base station, and remote station.

\section{Result and Discussion}

\subsection{Propagation Analysis between RSUP Sardjito and RSUD Wonosari using $144 \mathrm{MHz}$}

The two-way communication between RSUP Sardjito and RSUD Wonosari with the distance of $33.17 \mathrm{~km}$ can be worked but it is not continuous, with the electromagnetic field power is only $3.52 \mathrm{~dB} \mu \mathrm{V} / \mathrm{m}$. In the TX power of 5 Watt, it only produces S5 on the S-meter scale due to the blockage of the southern mountain in the Patuk area.

To get a continuous system, it needs a transmit power above 60 Watt with the antenna tower height above 50 meter. The best solution in this case is to use a repeater stations at the top of the southern mountain around Patuk area or Ngelanggeran area. 


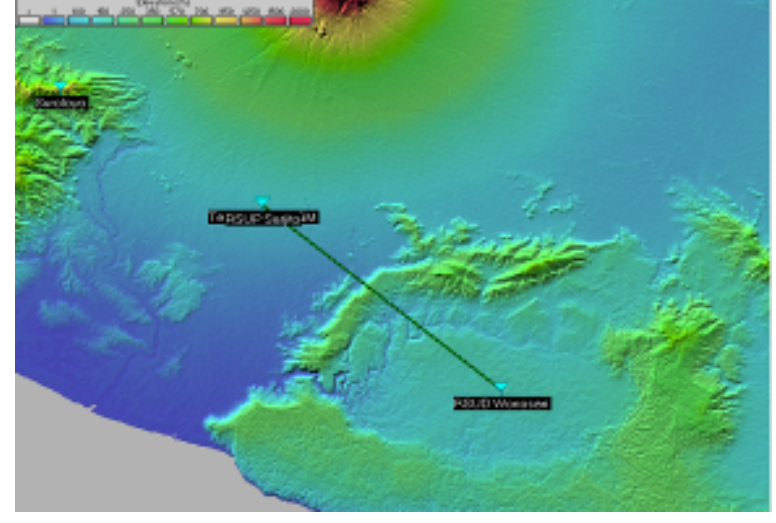

Fig. 1. Simulation using radio mobile to show the communication quality between Sardjito Hospital and District Hospital in Wonosari.

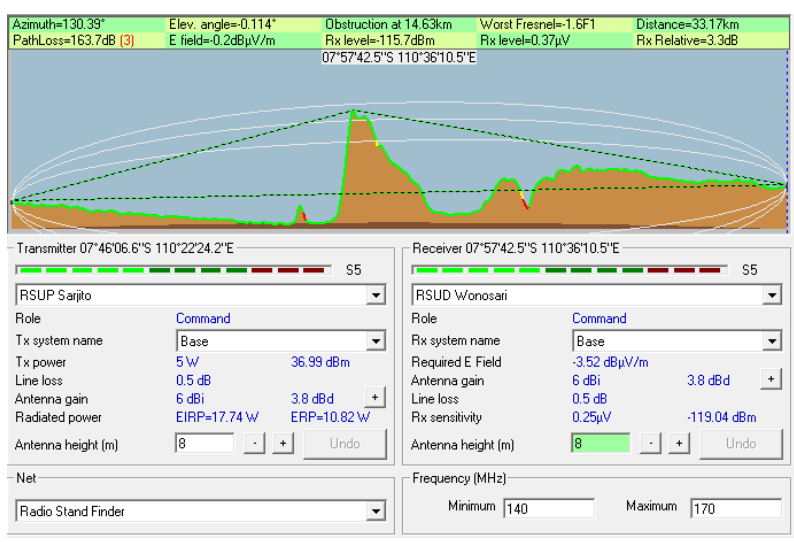

Fig. 2. The technical data of simulation using radio mobile to show the communication wuality between Sardjito Hospital and District Hospital in Wonosari on the frequency band of 144 MHz.

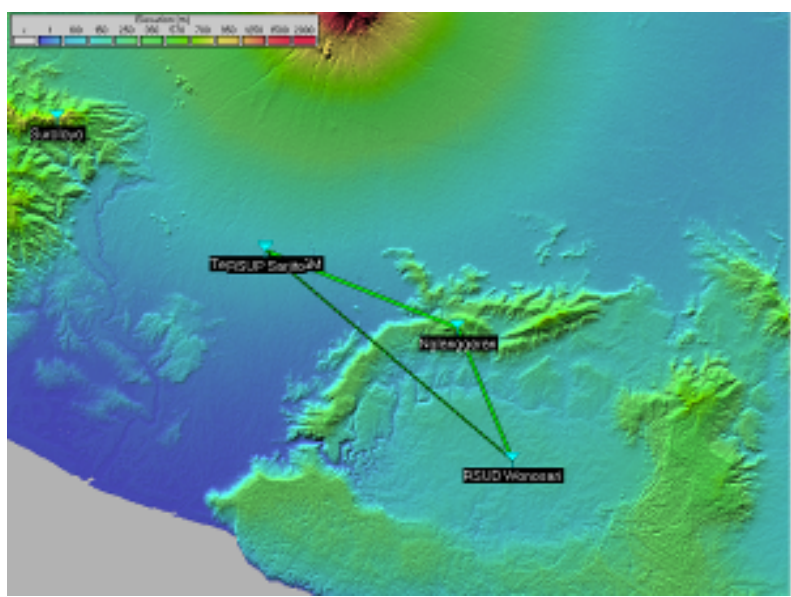

Fig. 3. Simulation using radio mobile to show the quality of communication between Sardjito Hospital and District Hospital in Wonosari in the frequency band of $144 \mathrm{MHz}$ with a repeater located at Ngelanggeran (green line indicates the successful communications)

\subsection{Propagation Analysis Sardjito Hospital and District Hospital in Wonosari using 7.08 MHz}

The two-way communication between RSUP Sardjito and RSUD Wonosari with the distance of $33.17 \mathrm{~km}$ can be done continuously, with the electromagnetic field power reaches $30.37 \mathrm{~dB} \mu \mathrm{V} / \mathrm{m}$ in the TX power of $100 \mathrm{Watt}$. It produces $\mathrm{S} 9$ on the S-meter scale. Although it is blocked by the southern mountain in the Patuk area, this communication can be continuous by using skywave as the same as the Fressnel postulate for the HF frequency.

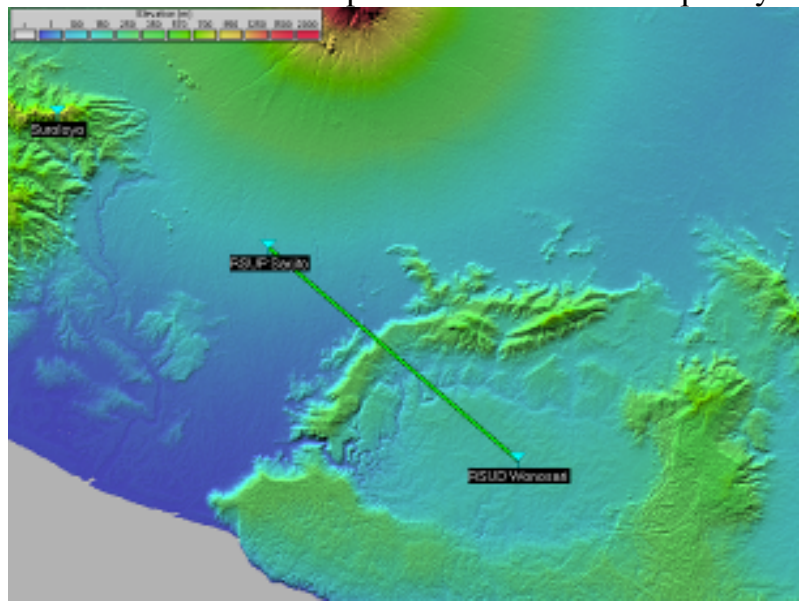

Fig. 4. Simulation using radio mobile to show the quality of communication between RSUP Sardjito and RSUD Wonosari in the frequency band of $7.08 \mathrm{MHz}$ (green line indicates that the communication is successfully done)

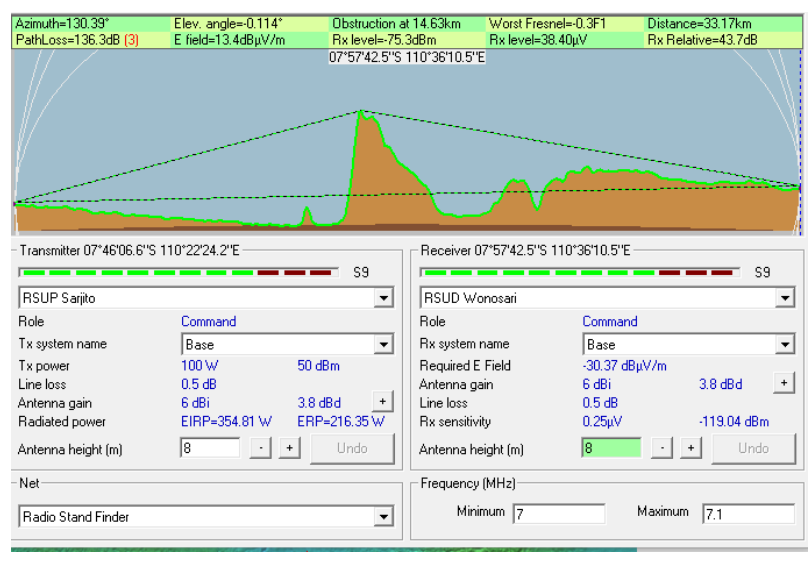

Fig. 5. The technical data of simulation using radio mobile to show the quality of communication between Sardjito Hospital and District Hospital in Wonosari in the frequency band of $7.08 \mathrm{MHz}$.

\subsection{Text Data Transmission}

The text data transmission is done using Mix.W 3.11g with the transmission mode in RTTY on the frequency of $144.148 \mathrm{MHz}$ and $7.08 \mathrm{MHz}$. The data needs to be sent is a text that converted into voice (digital-to-analog). The result of text data transmission is shown in Figure 6 and 7. 


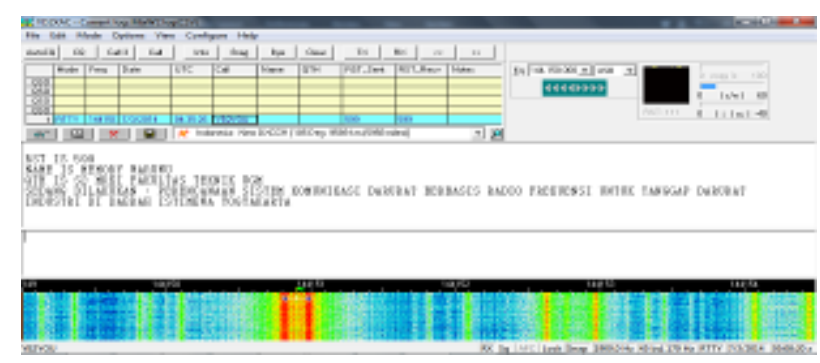

Fig. 6. The process of receiving text data using MixW 3.11g in the mode of RTTY (maximum signal power)

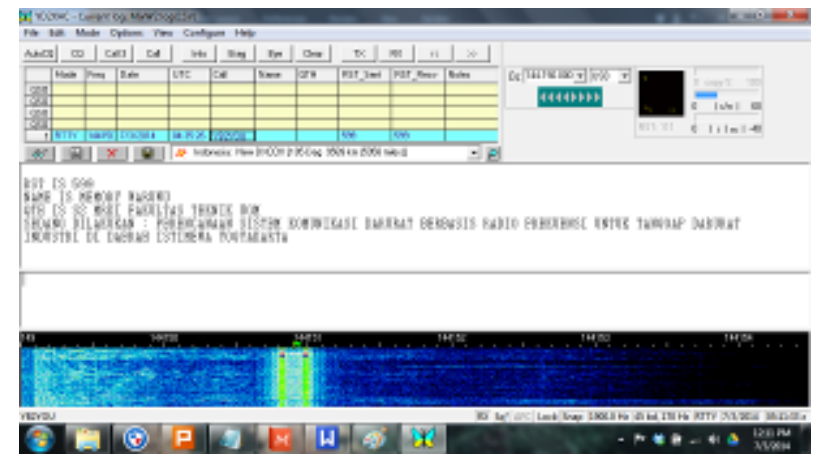

Fig. 7. The process of receiving text data using MixW 3.11g in the mode of RTTY (minimum signal power)

Table 1. Result of text data transmission

\begin{tabular}{|c|c|c|}
\hline $\begin{array}{c}\text { Distance } \\
(\mathbf{k m})\end{array}$ & $\begin{array}{c}\text { Percentage of text } \\
\text { data reception (\%) }\end{array}$ & Error (\%) \\
\hline 1 & 100.0 & 0.0 \\
\hline 5 & 100.0 & 0.0 \\
\hline 10 & 100.0 & 0.0 \\
\hline 15 & 97.0 & 3.0 \\
\hline 20 & 98.0 & 2.0 \\
\hline 25 & 96.0 & 4.0 \\
\hline 30 & 98.0 & 2.0 \\
\hline 35 & 94.0 & 6.0 \\
\hline 40 & 95.0 & 5.0 \\
\hline Average & 97.56 & 2.44 \\
\hline
\end{tabular}

Based on the Table 1, it shows that the result of data text transmission in the range of distance between 0 and $40 \mathrm{~km}$ reaches the average value of $97.56 \%$. The average error value produced by the system is $2.44 \%$. From those values, it can be concluded that the text data transmission is successfully conducted.

\subsection{Image Data Transmission}

The image data transmission is done using MixW 3.11g in the mode of SSTV. The result of image data transmission are shown in Figure 8 to Figure 10. Those images are analysed for the image quality after they are received by the receiver. The image quality can be measured by using a standard image pattern developed by EIA (Electronic Industries Association). This pattern is used to test several parameters in the image quality, as what explained by Grob (1984): "This standard pattern provides a reference for checking resolution, scanning linearity, interlacing, additional characteristics of the reproduced picture".

Here are some parameters to test the image quality:

a. Horizontal linearity

This parameter is tested by comparing the lines or horizontal shapes with the number and the size similar to the image data before and after the data transmission.

b. Vertical linearity

This parameter is tested by comparing the lines or the vertical shapes with the number and the size similar to the image before and after the data transmission.

c. Aspect ratio

This parameter is tested by comparing the ratio of the image size before and after the data transmission.

d. Contrast range

The 10-level grayscale shows a range from a maximum white to the $1 / 30^{\text {m }}$ of scale value. Then, data is compared before and after the data transmission.

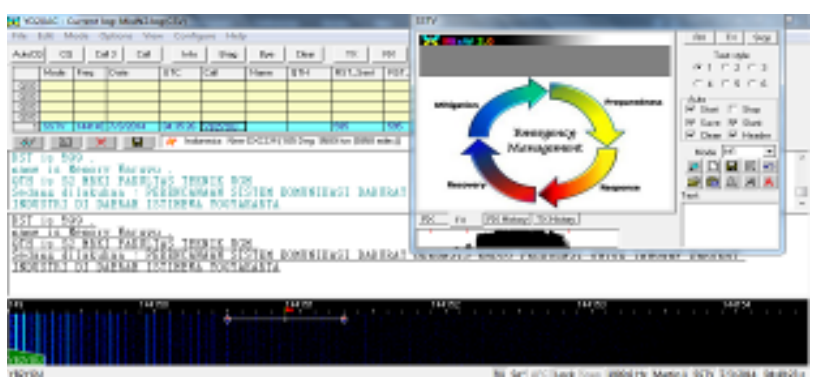

Fig. 8. The image data before it is sent using MixW 3.11g in the mode of SSTV

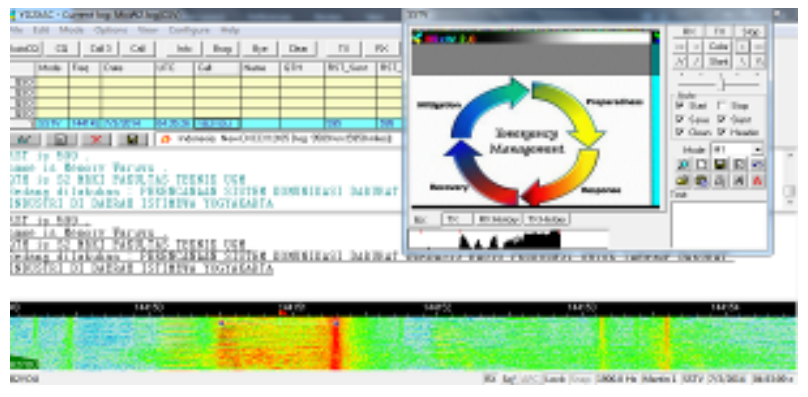

Fig. 9. The image data after it is received by the receiver (maximum signal power) 


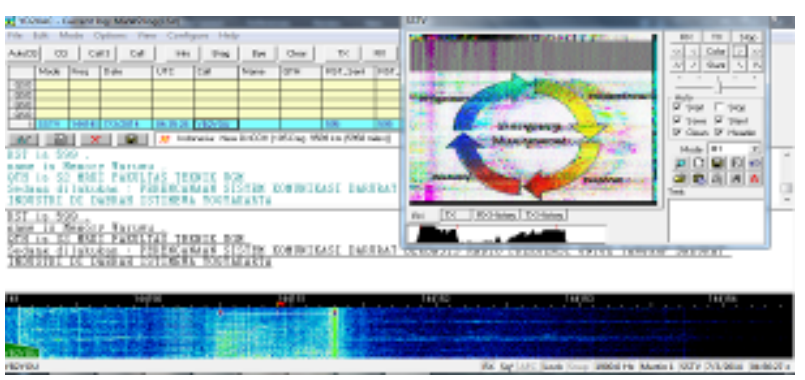

Fig. 10. The image data after it is received by the receiver (minimum signal power)

Table 2. The result of image data transmission

\begin{tabular}{|c|c|c|c|c|c|}
\hline \multirow{2}{*}{$\begin{array}{c}\text { Quality } \\
\text { Test } \\
\text { Factor }\end{array}$} & \multicolumn{5}{|c|}{ Percentage of image quality score (\%) } \\
\cline { 2 - 6 } & $500 \mathrm{~m}$ & $10 \mathrm{~km}$ & $\begin{array}{c}20 \\
\mathrm{~km}\end{array}$ & $30 \mathrm{~km}$ & $40 \mathrm{~km}$ \\
\hline $\begin{array}{c}\text { Horizontal } \\
\text { linearity }\end{array}$ & 90.5 & 80.3 & 78.1 & 75.2 & 57.6 \\
\hline $\begin{array}{c}\text { Vertical } \\
\text { linearity }\end{array}$ & 95.1 & 80.3 & 78.0 & 72.0 & 58.3 \\
\hline $\begin{array}{c}\text { Aspect } \\
\text { ratio }\end{array}$ & 99.6 & 94.0 & 84.7 & 80.4 & 75.0 \\
\hline $\begin{array}{c}\text { Contrast } \\
\text { range }\end{array}$ & 90.2 & 75.4 & 60.2 & 40.5 & 30.4 \\
\hline Average & 93.85 & 82.50 & 75.25 & 67.03 & 55.33 \\
\hline
\end{tabular}

Based on the result from Figure 8 to 10 and Table 2, it is concluded that the image data can be transmitted and received in the range distance from $500 \mathrm{~m}$ to $40 \mathrm{~km}$. But, there is a significant decrement in the number of image quality, from $93.85 \%$ to $55.33 \%$. That decrease is caused by frequency distortion and small gain when the image is transmitted. To solve that problems, the system is added with a filter during the transmission process along with the increment of amplitude gain so that the data can be sent in the best quality it can be.

\section{Conclusion}

This research focuses on the performance test of emergency data communication system by using several types of data. The system uses Very High Frequency (VHF) $144 \mathrm{MHz}$ and High Frequency (HF) 7.08 MHz as the data carrier and a software to interpret the text and image modulated onto the data carrier. Based on the results of the system's performance test between the Wonosari Gunungkidul District Hospital and the Sardjito Hospital with the distance of $40 \mathrm{~km}$, the receiving quality of the data transmission for text and image are $95 \%$ and $55.33 \%$, respectively. The recieved image can be recognized and identified.
We would like to thank the Laboratory of Sensor and Telecontrol System, Department Nuclear Engineering and Engineering Physics, Faculty of Engineering, Universitas Gadjah Mada, for supporting this research.

\section{References}

1. P.D. Wiedemeier, "Transmitting Medical Imagery over 2-Meter Amateur Packet Radio Networks using TCP Reno and UDP", IEEE-AC paper \#1067 Version 5, December (2007)

2. M. Uysal, M.R. Heidarpour, "Cooperative Communication Techniques for Future-Generation HF Radios", IEEE Communications Magazine Topics in Military Communications, October (2012)

3. J.L. Barber (N7CXI), "Proposal for SSTV Mode Specifications", presented at the Dayton SSTV forum in Silicon Pixels, May (2000)

4. A. Hapenciuc, P. Svasta, "Long Range Image Radio Transmitter", IEEE $19^{\text {th }}$ International Symposium for Design and Technology in Electronic Packaging (SIITME), 24-27 October (2013)

5. S.M. Dilek, A. Ayranci, R. Ata, O. Ceylan, H.B. Yagci, "Radio Transmitter Design including FPGA for Micro/Nano Satellite", IEEE 978-1-4673-55636/13/\$31.00 (2013)

6. A. Aziminejad, A.W. Lee, G. Epelbaum, "Radio Propagation Prediction for CBTC Data Communication Subsystem Design", IEEE Vehicular Technology Magazine 1556-6072/15, September (2015).

7. T. Bhattachatjee, S.P. Maity, A. Roy, "Prediction Error Based Secret Image Transmission Over Radio Mobile Channel", IEEE WiSPNET conference 978-14673-9338-6/16/\$31.00, June (2016)

8. S. Hawibowo, Sunarno, M.M. Waruwu, R. Wijaya, "Development of Data Communication System for Virtual Hospital Scheme between Public Health Centers at Remote Areas and Regency Public Hospital Based on Radio Frequency Communication", Journal of Theoretical and Applied Information Technology Vol. 84 No.2, ISSN: 1992-8645, February (2016). 